\title{
Excitotoxic cell death induces delayed proliferation of endogenous neuroprogenitor cells in organotypic slice cultures of the rat spinal cord
}

\author{
GL Mazzone ${ }^{1}$, M Mladinic ${ }^{1,2,3}$ and A Nistri ${ }^{*, 1,2}$
}

The aim of the present report was to investigate whether, in the mammalian spinal cord, cell death induced by transient excitotoxic stress could trigger activation and proliferation of endogenous neuroprogenitor cells as a potential source of a lesion repair process and the underlying time course. Because it is difficult to address these issues in vivo, we used a validated model of spinal injury based on rat organotypic slice cultures that retain the fundamental tissue cytoarchitecture and replicate the main characteristics of experimental damage to the whole spinal cord. Excitotoxicity evoked by $1 \mathrm{~h}$ kainate application produced delayed neuronal death (40\%) peaking after 1 day without further losses or destruction of white matter cells for up to 2 weeks. After 10 days, cultures released a significantly larger concentration of endogenous glutamate, suggesting functional network plasticity. Indeed, after 1 week the total number of cells had returned to untreated control level, indicating substantial cell proliferation. Activation of progenitor cells started early as they spread outside the central area, and persisted for 2 weeks. Although expression of the neuronal progenitor phenotype was observed at day 3, peaked at 1 week and tapered off at 2 weeks, very few cells matured to neurons. Astroglia precursors started proliferating later and matured at 2 weeks. These data show insult-related proliferation of endogenous spinal neuroprogenitors over a relatively brief time course, and delineate a narrow temporal window for future experimental attempts to drive neuronal maturation and for identifying the factors regulating this process.

Cell Death and Disease (2013) 4, e902; doi:10.1038/cddis.2013.431; published online 31 October 2013

Subject Category: Neuroscience

The majority of new spinal cord injury (SCI) cases show a mismatch between moderate neuronal cell death and severity of chronic symptoms like paralysis with sensory and autonomic dysfunction. ${ }^{1,2}$ As neuronal cell losses are limited, restorative strategies with stem and progenitor cells are under investigation for tissue repair and recovery in neonatal and adult $\mathrm{SCl}^{3-5}$ Major goals to understand how to repair the spinal cord tissue are clarification of the duration of the secondary lesion process and whether certain intrinsic cells may proliferate to compensate for damage and to obtain functional improvement. ${ }^{3}$ One of the early principal contributors to the lesional process is excitotoxicity due to excessive release of the excitatory transmitter glutamate $e^{6,7}$ that triggers a series of complex biochemical processes further amplifying the damage (secondary lesion). ${ }^{8,9}$

The adult spinal cord is derived from the caudal neural tube, which is initially composed of heterogeneous neuroepithelial cells surrounding a central lumen with distinct proliferative and differentiation potential. ${ }^{10}$ Although in a few regions of the adult mammalian brain, neurogenesis from multipotent progenitor cells occurs throughout life ${ }^{11}$ in the spinal cord this phenomenon is restricted to the area around the central canal and is rarely observed in the parenchyma. ${ }^{12} \mathrm{~A}$ recent study has shown that, in the adult mouse spinal cord, progenitors make up a small population comprising ependymal, astrocytic and oligodendrocytic lineages. ${ }^{13}$ The question then arises about the role that spinal progenitor cells may have in attempting damage repair after SCI. In the normal adult mouse, only ependymal cells show stem cell properties and multineage potential, although none of them is reported to finally evolve into a neuronal phenotype, as most display an oligodendrocytic profile. ${ }^{13}$ In the rat spinal cord, progenitors can proliferate to neurosphere-forming cells that, when grown in vitro, they can be transformed into neurons and glia. ${ }^{14}$ Although stem cells from embryonic and adult nervous systems appear similar in their differentiation process, ${ }^{15}$ it is unclear whether, after experimental $\mathrm{SCI}$, progenitor cells intrinsic to the spinal tissue can mature to neurons and glia and replace lost cells. It is difficult to study these questions with in vivo animal models that allow only limited experimental

\footnotetext{
${ }^{1}$ Department of Neuroscience, International School for Advanced Studies (SISSA), Trieste, Italy; ${ }^{2}$ SPINAL (Spinal Person Injury Neurorehabilitation Applied Laboratory), Istituto di Medicina Fisica e Riabilitazione, Udine, Italy and ${ }^{3}$ Department of Biotechnology, University of Rijeka, Rijeka, Croatia

*Corresponding author: A Nistri, Department of Neuroscience, International School for Advanced Studies (SISSA), Via Bonomea 265, Trieste 34136, Italy. Tel: +39 040 3787718; Fax: +39 040 3787702; E-mail: nistri@ sissa.it

Keywords: glial precursor; neuronal precursor; stem cells; kainic acid; spinal cord injury

Abbreviations: ANOVA, analysis of variance; AU, arbitrary unit; BrdU, bromodeoxyuridine; DAPI, 4',6-diamidino-2-phenylindole; DCX, double courting; DIV, days in vitro; DME/HIGH, Dulbecco's modified Eagle's medium high glucose; EdU, 5-ethynyl-20-deoxyuridine; FCS, fetal calf serum; GS, glutamine synthetase; Iba1, ionized calcium-binding adapter molecule 1; PBS, phosphate-buffered saline; NeuN, neuronal-specific nuclear protein; NGF, nerve growth factor; Ki67, proliferation marker antigen identified by the monoclonal antibody Ki67; S100, astroglial calcium-binding protein S100B; SCI, spinal cord injury; SEM, standard error of the mean Received 03.9.13; revised 26.9.13; accepted 27.9.13; Edited by A Verkhratsky
} 
access to the lesion evolution at serial time points after an acute $\mathrm{SCl}$ always produced, for ethical reasons, under general anesthesia that might partially constrain damage severity. To partially circumvent these problems, organotypic spinal cultures, that retain the basic spinal cytoarchitecture, have been used as an in vitro model of acute $\mathrm{SCl}$ induced by transient excitotoxicity with consequent moderate loss of neurons, minimal glial damage and strong impairment in endogenous glutamate release $24 \mathrm{~h}$ later. ${ }^{16,17}$ The short duration of excitotoxic stress is suggested to mimic the timeframe of clinical injuries usually treated with minimal delay in intensive care to restore metabolic dysfunction. The aims of the present study were to assess: (1) how long cell death continued beyond the first $24 \mathrm{~h}$; (2) whether any intrinsic progenitor cells could proliferate in response to excitotoxicity; (3) what their fate could be; and (4) whether they might restore the network ability to release the main excitatory transmitter glutamate essential for locomotor network function. ${ }^{18}$

\section{Results}

Endogenous release of glutamate following excitotoxicity. Previous experiments have indicated that kainate not only induces delayed excitotoxic cell death but is also a potent tool to evoke the release of endogenous glutamate (assessed with a real-time electrochemical assay) that is a useful, simple index of spinal network activity in culture. ${ }^{19}$ In the present study, we compared the glutamate releasing ability by $100 \mu \mathrm{M}$ kainate on long-term cultures that had been previously treated with the same kainate concentration versus naïve cultures (see protocol in Supplementary Figure S1a). Figure 1a shows that, on average $(n=8$ cultures), the releasing effect of $100 \mu \mathrm{M}$ kainate on formerly $(240 \mathrm{~h})$ treated cultures was very large with a time course characterized by an early peak and a slow decline to baseline. On the basis of the calibration tests, the peak current amplitude corresponded to $14.87 \pm 5.67 \mu \mathrm{M}$ extracellular glutamate ( $P=0.043$ versus naïve cultures). In contrast, average release of glutamate from naive cultures $(n=7)$ kept for equivalent time in vitro (240h) was very similar to the one observed at the normal start of the experiments (22 days in vitro, DIV) and amounted to an estimated $3.02 \pm 1.47 \mu \mathrm{M}$ concentration of glutamate. As these observations suggested spinal network plasticity (in analogy to the one developing in the human spinal cord), ${ }^{20}$ we further investigated the cell population at various times after the initial excitotoxic stimulus.

Time-dependent distribution of the neuronal loss. In all three slice regions, kainate significantly increased the occurrence of pyknotic nuclei (observed with 4',6-diamidino-2-phenylindole (DAPI) staining), a process already detectable at the end of $1 \mathrm{~h}$ application of kainate and intensified $24 \mathrm{~h}$ later despite intensive washout. ${ }^{17}$ Nevertheless, from the peak toxic effect observed $24 \mathrm{~h}$ after washout, the percent of pyknotic cells was gradually reduced in all three regions over the next 48-72 h (Figures $2 \mathrm{a}$ and b, gray and hatched bars). When pyknotic cells data from the three regions were pooled, the occurrence of pyknosis at
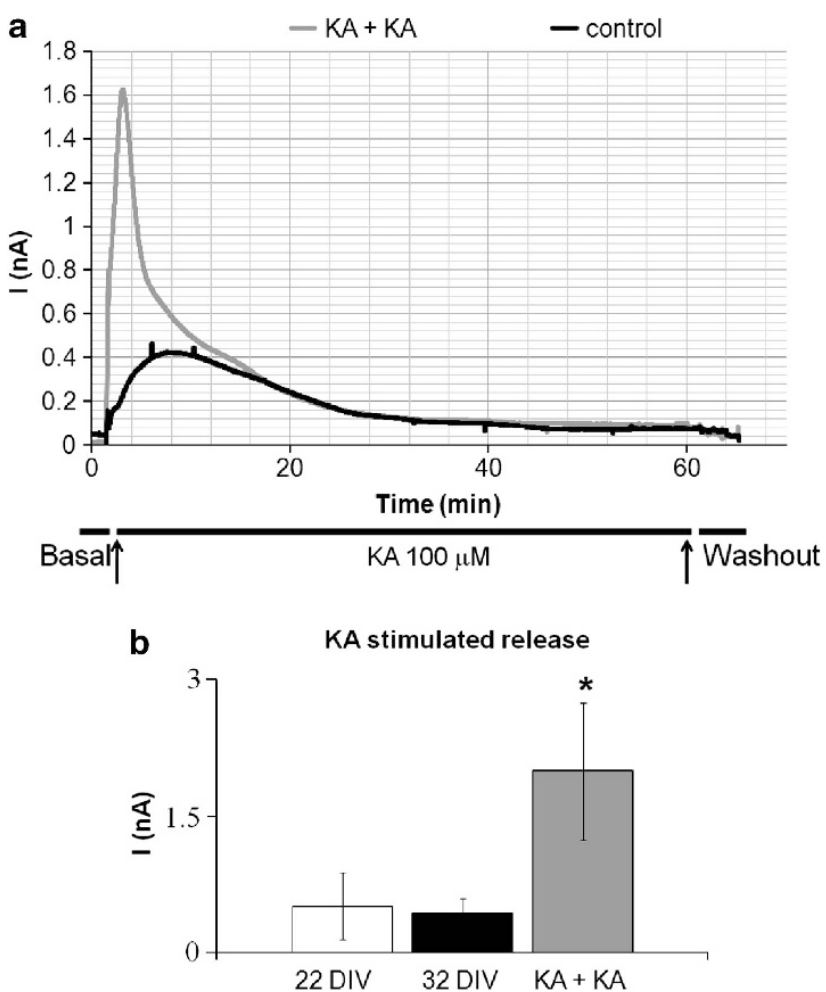

Figure 1 Glutamate release induced by kainate (KA) application on long-term cultures. (a) Average profile of endogenous glutamate release from slices exposed to $100 \mu \mathrm{M}$ kainate (applied within arrows) in control condition (treated only once at 32 DIV; black trace; $n=7$ ) and after a second KA application after the former KA treatment $(K A+K A$; gray trace; $n=8)$. The ordinate shows the redox current continuously monitored throughout the experiment with the glutamate biosensor in basic solution. Note the strong current response from on long-term cultures that had been previously treated $(K A+K A)$ versus control cultures. (b) Histograms showing the mean peak current obtained for different slices following $K A$ application for $1 \mathrm{~h}$ at 22 DIV $(n=4)$ and at 32 DIV in KA + KA $(n=8)$ or control condition $(n=7)$. ${ }^{*} P<0.05$ versus controls

$72 \mathrm{~h}$ after excitotoxic stimulation was as low as in the untreated controls and did not change even at longer time (336 h) in culture (Figure 2c). Together with the observation that cell death had stopped by $72 \mathrm{~h}$, there was, unexpectedly, a rebound in the total number of surviving cells (measured as non-pyknotic DAPI-positive elements) that was similar to the value of untreated controls $(316 \pm 30$ versus $344 \pm 27$, respectively, $n=5$ slices for each protocol). Even at $192 \mathrm{~h}$ after kainate, surviving cells were as many as in untreatedmatched cultures $(370 \pm 29$ versus $365 \pm 22$, respectively; $n=6-7$ slices for each protocol).

The number of neurons, identified because of their NeuN (neuronal-specific nuclear protein) nuclear positivity, fell $24 \mathrm{~h}$ after kainate application ${ }^{17}$ and remained stable thereafter (Figure 2d). Our data, thus, suggested that the incidence of neuronal loss in three spinal regions did not increase beyond $24 \mathrm{~h}$ as the number of surviving neurons remained constantly low. Nevertheless, because of the global number of cells eventually became similar to the one in control conditions, it seemed likely that excitotoxicity had elicited delayed cell proliferation in response to the initial damage. 

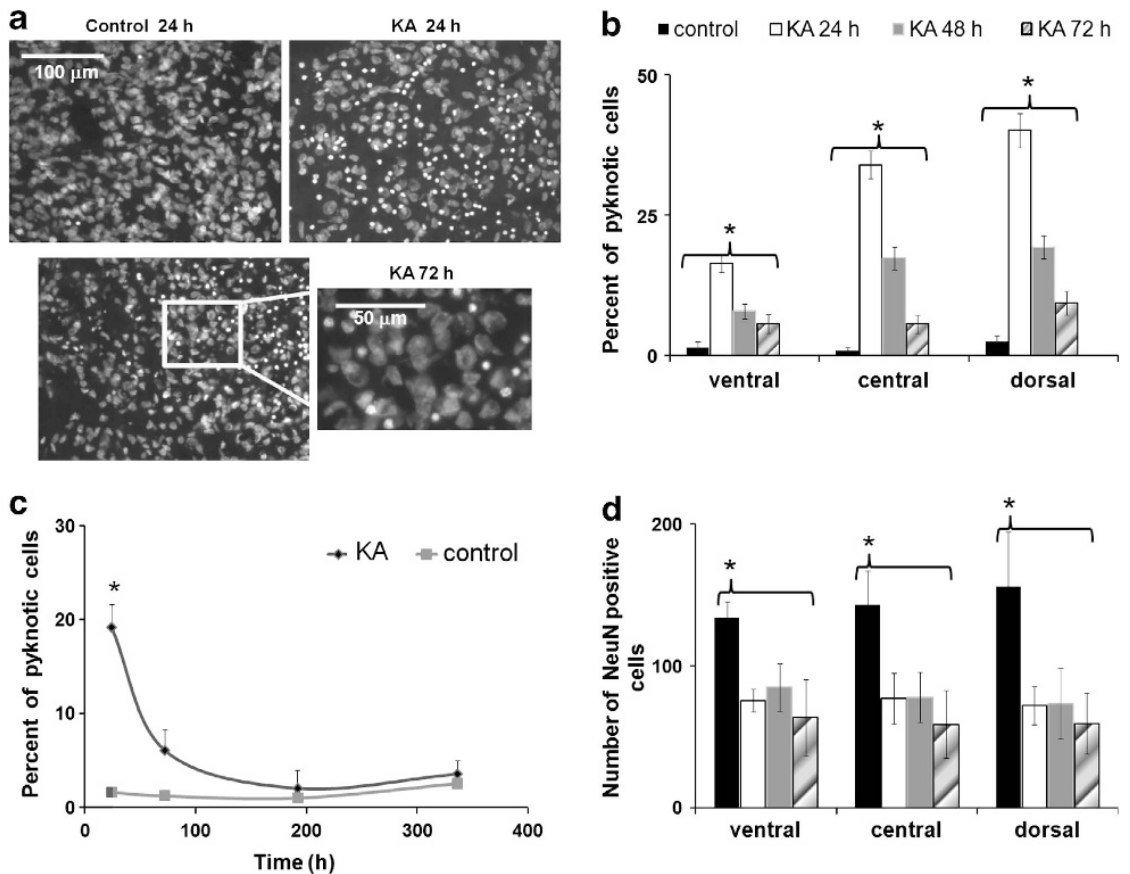

Figure 2 Cell losses evoked by kainate in long-term cultures. (a) Examples of DAPI nuclear staining for the central region in control condition, or after 24 or $72 \mathrm{~h}$ washout of kainate $(\mathrm{KA} ; 100 \mu \mathrm{M}$ for $1 \mathrm{~h})$. White dots indicate pyknotic nuclei. (b) Increased occurrence of cells with pyknotic nucleus after KA application in three slice regions, with maximum effect after $24 \mathrm{~h}$ and a gradual reduction over the next $48-72 \mathrm{~h}(n=8-14$ slices, from seven different experiments). Data are referred to the total number of DAPI-stained cells. (c) Plots showing the mean percent value for pyknotic cells in cryostat-cut sections during washout after KA application $(n=5-7$ slices, from at least three different experiments). (d) Histograms showing the number of NeuN-positive cells counted before KA application (control) and 24, 48 and $72 \mathrm{~h}$ after kainate washout in three slice regions ( $n=5-6$ slices, from at least four different experiments). ${ }^{*} P<0.05$ versus controls

Cell proliferation induced by kainate. This phenomenon was estimated by counting the number of Ki67 (proliferation marker antigen Ki67) positive nuclei, a validated marker expressed during all phases of the cell cycle (G1, S, G2 and $\mathrm{M}$, and absent in $\mathrm{G} 0) .{ }^{21}$ Figures $3 \mathrm{a}$ and $\mathrm{b}$ demonstrates that, $72 \mathrm{~h}$ after kainate, a significant increase in the number of Ki67-positive nuclei appeared in the three spinal regions. To further evaluate the number of dividing cells, we used the assay based on 5-ethynyl-20-deoxyuridine (EdU) incorporation into the DNA (see Materials and Methods). EdU was applied simultaneously with kainate (or to sham cultures) and maintained in culture for the following $24 \mathrm{~h}$ (see protocol scheme in Supplementary Figure S2a). In untreated controls at $72 \mathrm{~h}$, only a few EdU-positive cells were observed (Figure $3 \mathrm{c}$ ) and were localized to the region of the ventral fissure. At the same time point (Figure 3d), kainate treatment significantly increased the number of EdU-positive cells (over the global DAPI-positive population) that had a scattered distribution (Figure 3c, right). One week later (192h), EdU-positive cells were even more numerous particularly after kainate treatment (Figure 3d).Validation of these results was obtained by observing also bromodeoxyuridine (BrdU) incorporation into the DNA of dividing cells (see protocol in Supplementary Figure S2b) at $72 \mathrm{~h}$ in analogy with the data obtained with the EdU method (Figure 3e). Globally, these results suggest that transient kainate application enhanced delayed and sustained cell proliferation in the spinal cord organotypic culture and prompted us to characterize the new cell types.
Glial phenotypes observed after kainate treatment. Figure $4 \mathrm{a}$ (left) and b shows that, at $72 \mathrm{~h}$, in control conditions nearly half of the relatively small number of EdU-positive cells were also S100 (astroglial calcium-binding protein $\mathrm{S100B}$ ) positive, a cytoplasmic $\mathrm{Ca}^{2+}$ binding protein strongly expressed by astrocytes. ${ }^{22}$ Seventy-two hours after kainate treatment (Figure 4a (right) and b), despite the larger number of EdU-positive cells, the number of astrocytes that were EdU-positive remained as low as control (see also Figure 4b). Although a significant increase in S100 cytoplasmic immunoreactivity signal was observed $72 \mathrm{~h}$ after kainate (Figure 4d), no change was detected in immunoreactivity for vimentin (Supplementary Figures S3a and b) used as a marker for progenitor cells. ${ }^{23}$ When glutamine synthetase (GS), a standard cytoplasmic marker for astrocytes in the brain and spinal cord, ${ }^{24,25}$ was analyzed, no statistically significant change in immunoreactivity was observed $72 \mathrm{~h}$ after kainate (Supplementary Figures S3c and $\mathrm{d}$ ). Two weeks after kainate $(336 \mathrm{~h})$, the number of EdU-positive cells that co-expressed S100 (Figures 4a and c) significantly grew with respect to sham controls, indicating delayed proliferation of S100-positive cells, whereas the S100 immunoreactivity signal was analogous to untreated controls (Figure 4e). This observations support the dissociation between the number of lately proliferating astrocytes and the S100 signal strength.

Using Iba1 (ionized calcium-binding adapter molecule 1) as biomarker for microglia, ${ }^{26}$ there was no significant change in the number of lba1-positive cells after $72 \mathrm{~h}$ from kainate washout, as they remained a rather small fraction of the slice population ${ }^{22}$ 

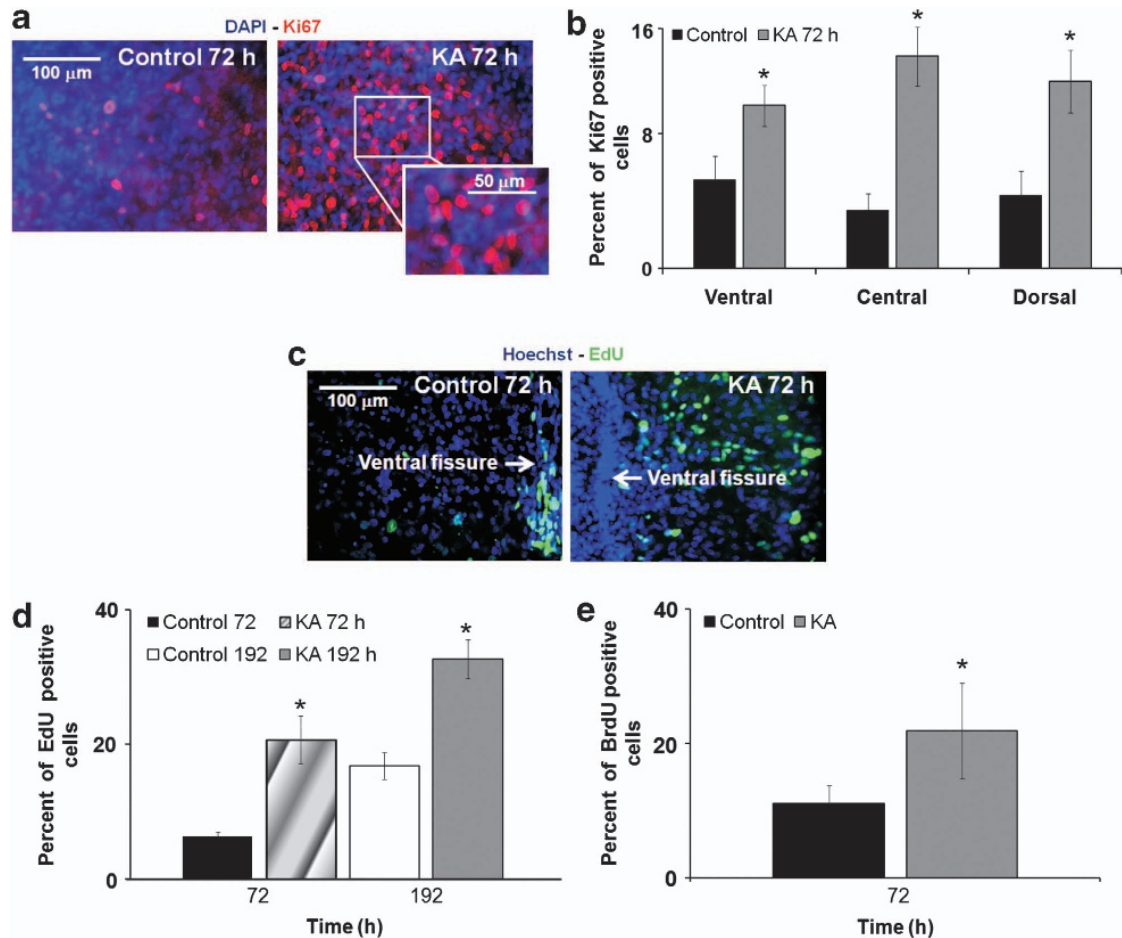

oechst - EdU

Figure 3 Cell proliferation induced by kainate on long-term cultures. (a) Examples of Ki67 staining (red) and DAPI-positive cells (blue) in the central region $72 \mathrm{~h}$ after kainate application. (b) Histograms showing the percent value of Ki67-positive cells over total number of cells. Ki67-positive cells were significantly increased in all three spinal cord regions ( $n=8-10$ slices, from four different experiments, ${ }^{*} P<0.05$ versus control). (c) Representative EdU-stained cells (green) in control condition (left). Hoechstpositive cells are shown in blue. Note clustering of EdU-positive cells at the central fissure. Right, $72 \mathrm{~h}$ after kainate application (KA; $100 \mu \mathrm{M}$ for $1 \mathrm{~h}$ ), EdU-positive cells show scattered distribution. (d) Histograms show the percent number of EdU-positive cells over total number of cells after $72 \mathrm{~h}$ kainate wash or control ( $n=5 \mathrm{slices,}$, from two different experiments, ${ }^{*} P=0.0016$ versus control at $72 \mathrm{~h} ;{ }^{*} P=0.008$ versus control at $192 \mathrm{~h}$ ). (e) Histograms show the percent number of BrdU-positive cells over total number of cells after $72 \mathrm{~h}$ of kainate washout ( $n=3-5$ slices, from two different experiments, ${ }^{*} P<0.05$ versus control)

as shown in Figures $5 \mathrm{a}$ and b. However, we observed a morphological change in microglia $24 \mathrm{~h}$ after kainate because a significant increase in the number of microglial branches and endpoints was observed (Figures $5 \mathrm{c}$ and d). ${ }^{27}$

Neuronal phenotype after kainate treatment. Developing neurons are typically identified by the biomarker double courting (DCX), a cytoplasmic protein that regulates microtubule dynamics and processes involved in neuronal migration and fiber outgrowth, and that first appears at 10.5 embryonic day. ${ }^{28}$ Once neuronal migration and maturation are complete, DCX expression is strongly reduced and neurons are conventionally identified by the nuclear marker NeuN. ${ }^{29}$ At 72, 192 and $336 \mathrm{~h}$ after kainate (Figures 6a-d), a minority of EdU-positive cells also expressed DCX, reaching a maximum at $192 \mathrm{~h}$, and tapering off at $336 \mathrm{~h}$ (Figures $6 \mathrm{~b}-\mathrm{d}$ ). At the time $(192 \mathrm{~h})$ of the largest expression of DCX-positive cells, the average number of neurons was $170 \pm 13$ in control and $84 \pm 10$ after kainate ( $n=8$ slices), that is, values similar to those found at 24-72 h (Figure 2), suggesting that there had been no concomitant change in the global neuronal population. Thus, after the excitotoxic stimulus, a few proliferating progenitor cells showed their potential to mature into neurons within a limited time window.

To measure how many neuronal progenitors actually became neurons, we examined the number of NeuN-positive cells also stained for EdU. As shown in Figure 7, at $72 \mathrm{~h}$, although the number of new cells was significantly higher following kainate application than in control (Figures 7a and b), the number of new neurons was very small and similar to control. At $336 \mathrm{~h}$ after kainate, although the number of new cells had increased (Figures $7 \mathrm{a}$ and $\mathrm{c}$ ) when compared with the value observed at $72 \mathrm{~h}$, the average number of new neurons remained, however, very small. In fact, at $336 \mathrm{~h}$ the global number of neurons was $98 \pm 10$ after kainate versus $139 \pm 10$ in matched untreated controls $(n=7)$. Hence, the simplest interpretation of these data was that most DCX-positive cells had failed to mature into neurons despite continuous cell proliferation even after 2 weeks from kainate treatment.

\section{Discussion}

The present report shows that organotypic cultures of the rat spinal cord, that are a useful model to study cell death after excitotoxicity, ${ }^{17}$ manifested delayed proliferation of neuroprogenitors into astroglia, and their failure to generate new neurons. These results suggest that future experimental attempts to stimulate maturation of endogenous progenitors into neurons should be concentrated to a narrow time window after the acute lesion.

Delayed effects of spinal cord damage. Studying the time course of early effects originating after $\mathrm{SCl}$ is a complex task because in vivo animal experiments are usually unsuitable 

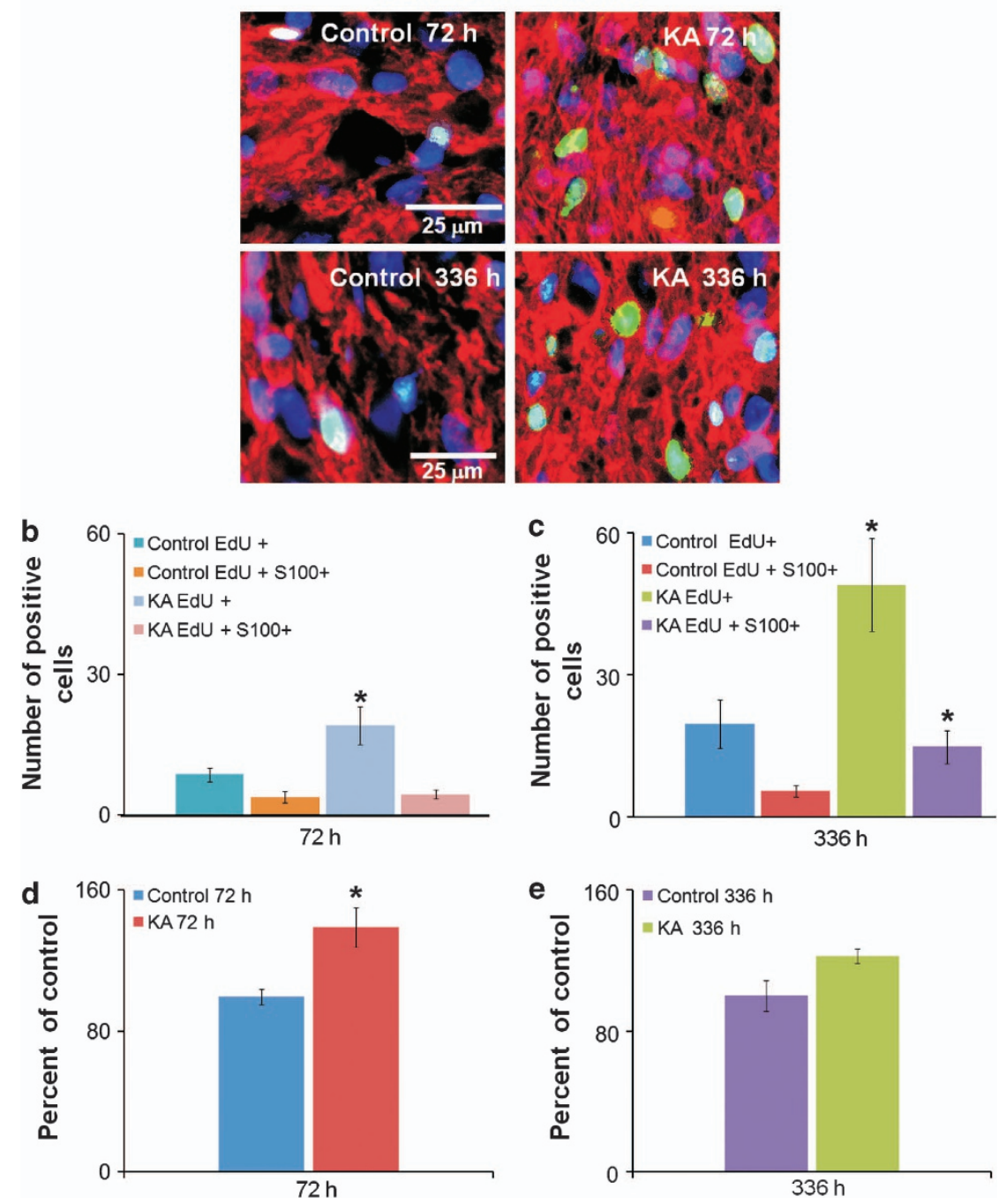

Figure 4 Glial cell proliferation after kainate treatment. (a) Examples of images showing EdU (green), S100 (red) and Hoechst-positive (blue) cells after 72 or $336 \mathrm{~h}$ washout of kainate. ( $\mathbf{b}$ and $\mathbf{c}$ ) Histograms indicate the number of EdU-positive cells that also are stained for $\mathrm{S} 100$ at $72 \mathrm{~h}$ ( $\mathbf{b}, n=3$ slices, from two different experiments, ${ }^{*} P=0.031$ versus control) or $336 \mathrm{~h}$ (c, $n=5$ slices, from two different experiments, ${ }^{*} P<0.05$ versus control) after kainate or in control condition. Note delayed glial proliferation indicated by late increment in EdU-positive and S100-stained cells. (d and e) Histograms show increase in S100 mean fluorescence intensity (arbitrary unit, AU), expressed as percent of control, at $72 \mathrm{~h}$ (d, $n=3-6$ slices, from two different experiments, ${ }^{*} P=0.003$ versus control) or $336 \mathrm{~h}$ (e, $n=5$ slices, from two different experiments) after kainate. Note increased $\mathrm{S} 100$ signal in KA-treated slices at $72 \mathrm{~h}$ but not $336 \mathrm{~h}$ after kainate

for repeated neuropathological sampling, and isolated spinal cord preparations survive in vitro for up to $24 \mathrm{~h}$ only. ${ }^{30}$ Excitotoxicity of organotypic cultures of the rat spinal cord $^{17}$ closely mimics the main pathophysiology of the rat spinal cord in vivo during the first few hours after $\mathrm{SCl}^{31}$ and triggers neuronal death via a process termed parthanatos. ${ }^{32}$ Of course, this is a simplified system that lacks blood supply (and, thus, blood-borne substances) and immunological reactions, which are important processes in vivo. ${ }^{33}$ The low number of microglial cells remained unchanged and was associated with their enhanced ramification ${ }^{34}$ that is a dynamic process observed early after brain injury, ${ }^{35}$ and attributed to targeted phagocytosis. ${ }^{27}$

Cell proliferation after kainate excitotoxicity. We investigated how the organotypic culture cell population changed after the first day following transient excitotoxicity, which is known to affect primarily neurons and to spare glia. ${ }^{16,17}$ Notwithstanding the region-specific number of neurons, ${ }^{22}$ the neuronal damage evoked by kainate was proportionally uniform, completed within $24 \mathrm{~h}$, and remained stable during the subsequent days and weeks. Cell death was therefore minimal at longer intervals. The initial damage was, however, sensed by the in vitro network that, via cell proliferation, re-established, after 1 week, the global number of cells as observed in sham controls.

To seek further evidence for cell proliferation, we counted the number of Ki67-positive elements because this biomarker is a sensitive tool to evaluate progenitor cells that can evolve into neurons or glia. ${ }^{36} \mathrm{Ki67}$-labeled cells were always a clear minority $(<10 \%)$ of the global cell population, but they were comparatively more numerous (two or three times more in all 


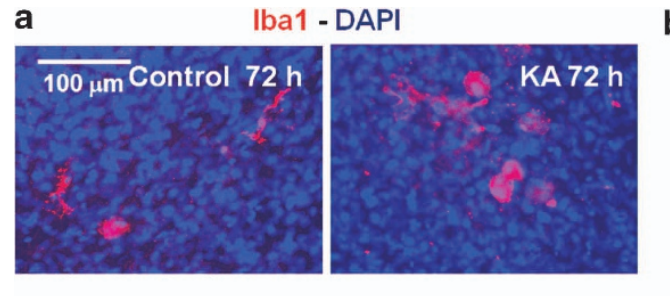

Iba1 - DAPI
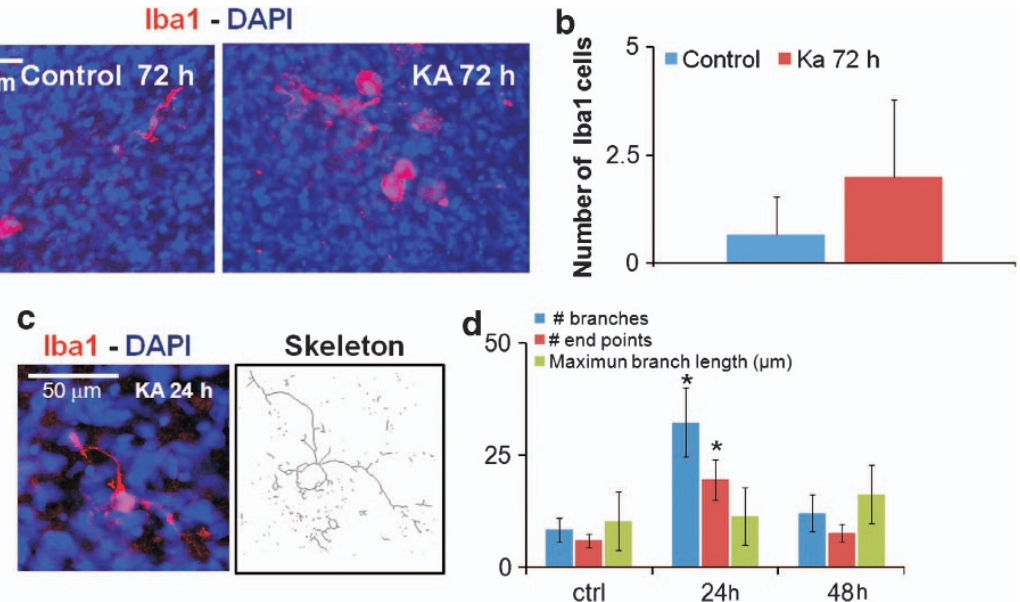

Figure 5 Examples of immmunohistochemical staining showing lba1 (a, red) and DAPI-positive (blue) cells $72 \mathrm{~h}$ after washout of kainate or in control. (b) Histograms showing the average number of Iba1-positive cells counted before kainate application (control) or $72 \mathrm{~h}$ after kainate wash. Note the relative low number of Iba1-positive cells (in accordance with our former study ${ }^{22}$ ). Morphological characterization of microglia was done with the skeleton method. ${ }^{27}$ (c) Quantification of lba1 morphology shows increase in the number of branches and end points, without alteration of the maximum branch length $\left({ }^{*} P<0.05\right.$ versus control)
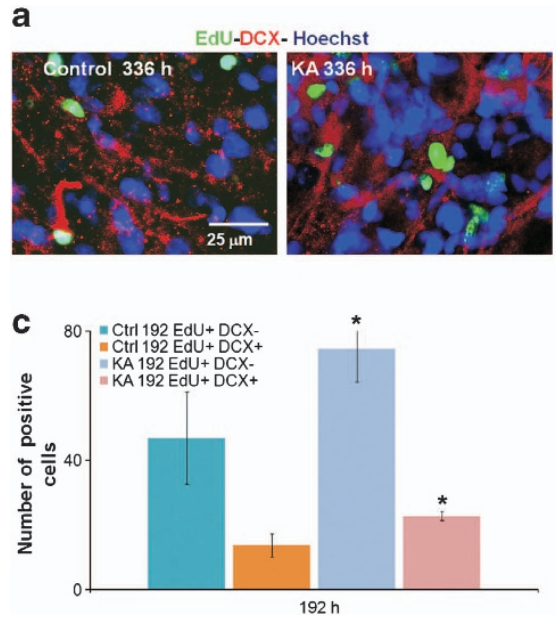
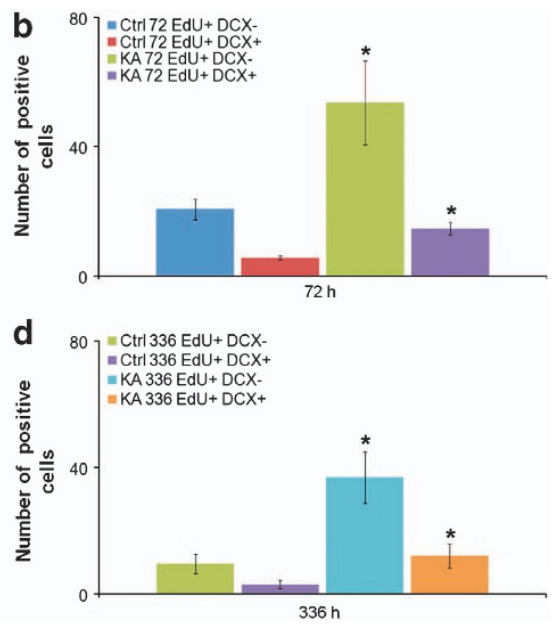

Figure 6 DCX-expressing cells indicate potential neurogenesis after kainate application. (a) Examples of EdU (green), DCX (red) and Hoechst-positive (blue) cells after kainate application and $336 \mathrm{~h}$ wash. (b-d) Histograms showing the number of DCX-positive cells over the total EdU-positive nuclei found at 72 (b, $n=3$ slices, from two different experiments, ${ }^{\star} P<0.05$ versus control), $192 \mathrm{~h}\left(\mathbf{c}, n=3\right.$ slices, from two different experiments, ${ }^{*} P<0.05$ versus control) or $336 \mathrm{~h}$ (d, $n=4$ slices, from two different experiments, ${ }^{*} P<0.05$ versus control). Note increased number of DCX-positive cells in KA-treated slices as compared with control at each time point

spinal areas) $72 \mathrm{~h}$ after kainate. We next assessed Ki76 cells proliferation by analyzing the incorporation of selective DNA biomarkers (EdU or BrdU) (http://www.sendcockpit.com). In control conditions, EdU-positive cells were particularly found near the central fissure that corresponds anatomically to the region around the spinal central canal, from where they spread out after injury. Hence, the simplest interpretation is that an experimental lesion had triggered activation and proliferation of cell precursors intrinsic to the spinal tissue. The next question was their fate.

Astroglia proliferation. The in vivo rat $\mathrm{SCl}$ model results in astrogliosis, neuronal and oligodendroglial cell death, axonal degeneration and demyelination that collectively lead to significant spinal cord tissue loss and consequently the formation of a central cavity at the chronic stage of injury (i.e., around 4 weeks or more after $\mathrm{SCl}$ ). ${ }^{8,37}$ Our focus was to find out how intrinsic cells reacted over a critical, earlier stage of $\mathrm{SCl}$ with a view of devising future experimental approaches to hinder the pathological process progression. GS has also been implicated as a hallmark of reactive astrocytosis, by its critical role in the glutamate catabolism following $\mathrm{SCl}^{25}$ However, no difference in GS immunostaining $72 \mathrm{~h}$ after kainate was observed in the present study, even if GS is suggested to be involved in the endogenous mechanism of protection against neurotoxicity after $\mathrm{SCl}$ in vivo. ${ }^{25}$ The persistence of the GS immunoreactivity confirms our previous studies ${ }^{30,32}$ that excitotoxicity primarily damages 

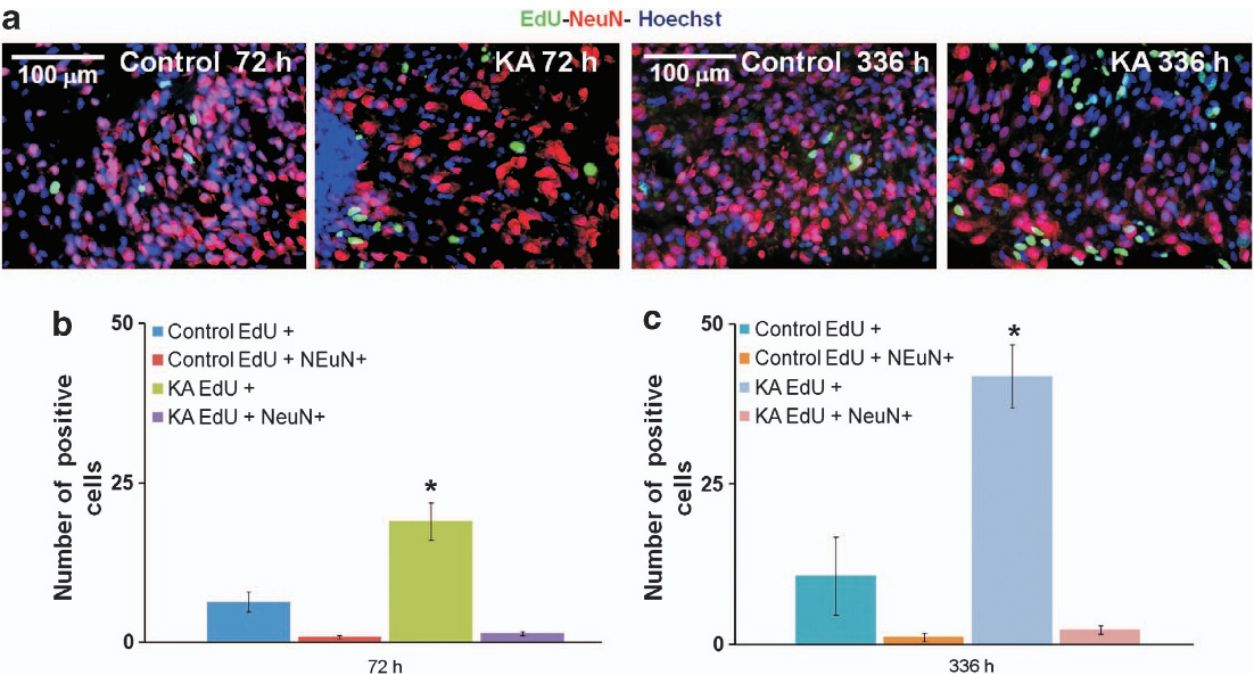

Figure 7 Lack of neuronal progenitor maturation after kainate. (a) Representative NeuN (red), EdU (green) and Hoechst-positive (blue) cells in control condition or after kainate application followed by 72 or $336 \mathrm{~h}$ washout. (b and $\mathbf{c}$ ) Histograms showing the number of EdU-positive cells with or without NeuN labeling at $72 \mathrm{~h}$ (b, $n=3 \mathrm{slices}$, from two different experiments, ${ }^{*} P=0.001$ versus control) and $336 \mathrm{~h}$ (c, $n=5-6$ slices, from two different experiments, ${ }^{*} P=0.017$ versus control). Note that the number of new neurons was very small and similar to control after 72 or $336 \mathrm{~h}$ washout

neurons rather than glia in the rat spinal cord. Our current results showing a transient, early increase in the S100 signal accord with recent clinical data that underlie the importance of high serum $\mathrm{S} 100$ levels as a biomarker of brain lesions affecting astroglia. ${ }^{38}$

To further investigate the contribution by astroglia to excitotoxicity following kainate administration, we found EdU-positive cells with S100 immunoreactivity suggestive of astroglia proliferation only after 2 weeks in culture. Interestingly, despite the lack of early association between S100 and EdU staining and no early increase in immunoreactivity for the precursor marker vimentin, the strength of the S100 fluorescence signal was enhanced 3 days after kainate. As recently reviewed, ${ }^{38}$ there is ample evidence for the role of S100 in brain injury, whereby this protein not simply leaks out from damaged cells, but it is actively secreted in response to damage so that its detection in biological fluids makes it a biomarker for active cell injury in the nervous system. In the current study, the simplest explanation is that glial cells reacted with stronger expression of $\mathrm{S} 100$ before their progenitor proliferation. A late increase in glial cells likely contributed to the recovery in cell numbers observed after 1 week from the initial kainate application.

Neuronal progenitors. DCX-immunoreactive neuronal precursors started proliferating already at $72 \mathrm{~h}$ from the excitotoxic stress and reached a maximum at $192 \mathrm{~h}$, after which their number decreased. These observations differ from a recent study of sustained ( $24 \mathrm{~h}$ ) excitotoxic injury to rat organotypic hippocampal slices, where cell death continued for up to 7 days, astroglial proliferation was lacking and DCX expression increased, although the actual number of surviving neurons was not reported. ${ }^{39}$

The present investigation shows that most DCX-positive precursors failed to mature into neurons, so that this process was inadequate to recreate the original neuronal number. This finding accords with studies of long-term survival of brain neurons as about $80 \%$ of the stroke-generated new striatal neurons die during the first 2 weeks after their formation. ${ }^{40}$ This result is probably due to the deleterious pathological environment surrounding the new neurons ${ }^{41}$ in vivo as much as in vitro. In brain networks, kainate evokes neuronal death followed by plasticity rearrangement with delayed onset of spontaneous seizures. ${ }^{42}$ Enhanced network excitability is reported after $\mathrm{SCl}$ even in areas remote from the primary lesion. ${ }^{43}$ This phenomenon is compatible with the large increase in glutamate release we detected long after kainate treatment. Although future studies are necessary to identify the precise mechanisms underlying the facilitated release of glutamate, this process probably originated from the reverse operation of glutamate carriers on glial and neuronal membranes as described after SCl in vivo ${ }^{44,45}$ and it may be correlated to hyperexcitability of glutamatergic networks during the secondary phase of $\mathrm{SCl} .^{20,46,47}$

\section{Conclusions}

As acute $\mathrm{SCl}$ results in rapid loss of neurons within the first day, ${ }^{9,48}$ network reconstruction through cell replacement is an attractive target to produce functional recovery. ${ }^{49,50}$ Although much work is focussed on transplanted stem cells especially as a major source of factors promoting recovery after $\mathrm{SCI},{ }^{51,52}$ little is known about their role of endogenous stem cells after $\mathrm{SCl}^{3}$ The present report suggests that, after excitotoxic damage, progenitor cells could proliferate for a limited time only and most failed to mature into neurons. This observation delineates a time window for exploring how to drive their full maturation and, thus, provides a convenient test system for experimenting genomic or proteomic approaches to improve the outcome of progenitor cell treatment. 


\section{Materials and Methods}

Preparation and maintenance of organotypic cultures. Spinal cord organotypic slices were prepared from embryos (at 13 days of gestation) of pregnant Wistar rats as previously reported. ${ }^{17,53}$ Briefly, the fetuses were delivered by caesarian section from timed-pregnant rats killed by slowly raising levels of $\mathrm{CO}_{2}$. Approval for these experiments was obtained from the Scuola Internazionale Superiore di Studi Avanzati (Trieste, Italy) Ethical Committee. All efforts were made to reduce the number of animals used and to minimize animal suffering.

Culture slices were grown in a medium containing $82 \%$ Dulbecco's Modified Eagle medium (DME/HIGH (Dulbecco's modified Eagle's medium high glucose);

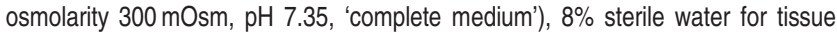
culture, $10 \%$ fetal bovine serum (FBS; Invitrogen, Milano, Italy), $5 \mathrm{ng} / \mathrm{ml}$ nerve growth factor (NGF; Alomone Laboratories; Jerusalem, Israel) and maintained in culture for 22 DIV in accordance with standard procedures. ${ }^{54,55} \mathrm{DME} / \mathrm{HIGH}$, penicillin and streptomycin were purchased from Euroclone (Paignton, UK). Fetal calf serum (FCS) was obtained from Invitrogen. Unless otherwise indicated, other reagents were purchased from Sigma-Aldrich, Milan, Italy.

Protocol for excitotoxic injury on organotypic cultures. Supplementary Figures S1 and S2 summarize the experimental protocols used for the current study. Acute excitotoxicity injury was produced, at 22 DIV, by applying kainate for $1 \mathrm{~h}(100 \mu \mathrm{M}$; Ascent Scientific, Bristol, UK) dissolved in complete culture medium and then carefully washed out with complete medium. Following kainate washout, cultures were used for electrochemical experiments (Supplementary Figure S1a) and/or immunohistochemistry studies (Supplementary Figure S1b). Control preparations (sham) were, in each experiment, untreated sister cultures maintained in vitro for the same time points and subjected to the same medium washout.

Electrochemical glutamate release. In accordance with our previous report, ${ }^{19}$ the release of glutamate was measured by using electrochemical biosensors (Sarissa Biomedical Ltd, Coventry, UK). On-line records were integrated with a potentiostat (Pinnacle Technology Inc., Lawrence, KS, USA) and analyzed off-line with PAL software (V1.5.0; Pinnacle Technology Inc.). We used glutamate and null biosensors (for specific and non-specific electroactive measurements) that were placed at each side of the ventral fissure. The specificity of the glutamate sensor was validated by using a glutamate calibration curve $(0.5-50 \mu \mathrm{M})$ and a single point calibration (with $50 \mu \mathrm{M}$ ) was repeated at the end of each experimental day. Glutamate release was recorded using a basic solution (containing in $\mathrm{mM}: \mathrm{NaCl}, 152 ; \mathrm{KCl}, 5 ; \mathrm{CaCl}_{2}, 2 ; \mathrm{MgCl}_{2}, 1$; HEPES, 10; glucose, 10, pH 7.4; 300-320 mOsm; Sigma-Aldrich, Milan, Italy). The basal glutamate release value was obtained after stabilizing the sensor on the slice for a few minute. Supplementary Figure S1a summarizes the experimental protocol used for this study. The redox current related to glutamate release was induced by kainate $(100 \mu \mathrm{M}$ for $1 \mathrm{~h}$ ) in control slices (at $32 \mathrm{DIV}$ ) or slices (at 32 DIV) that had received the first application of kainate at 22 DIV.

Organotypic slice immunostaining and cell counting. As previously described, ${ }^{22}$ cultures were fixed in $4 \%$ paraformaldehyde for $60 \mathrm{~min}$ at room temperature and stored in phosphate-buffered saline (PBS) until use or in $30 \%$ sucrose PBS for cryoprotection $\left(24 \mathrm{~h}\right.$ at $\left.4{ }^{\circ} \mathrm{C}\right)$. Cryoprotective slices were cryostat-sectioned to obtain, on average, 6-8 tissue sections (16 $\mu \mathrm{m}$ thick) from each organotypic culture, which were collected sequentially on histology slides.

Immunohistochemistry experiments were performed in accordance with previous reports. ${ }^{17,22}$ Slices were blocked with $3 \%$ FCS, $3 \%$ bovine serum albumin (BSA), $0.3 \%$ Triton in PBS (blocking solution) for $1 \mathrm{~h}$ at room temperature, followed by overnight incubation at $4{ }^{\circ} \mathrm{C}$ in a blocking solution containing the previously validated primary antibodies using the following dilutions: NeuN (1:250; Millipore, Billerica, MA, USA), Ki67 (1:100; Abcam, Cambridge, UK), Iba1 (1:750; Wako, Osaka, Japan), vimentin (1:200, Abcam), GS (1:300, Millipore); S100 (1:1000; Dako, Glostrup, Denmark), BrdU (1:100, Sigma) and DCX (1:100, Santa Cruz Biotechnology, Heidelberg, Germany; and 1:1000, Abcam). The primary antibody was visualized using a secondary fluorescent antibody (Alexa Fluor 488 or 594 at 1:500 dilution; Invitrogen, Carlsbad, CA, USA). To visualize cell nuclei, slices were incubated with 4', 6-diamidino-2-phenylindole (DAPI, $1 \mu \mathrm{g} / \mathrm{ml}$; Sigma) or Hoechst 33342, ( $5 \mu \mathrm{g} / \mathrm{ml}$; Invitrogen, Milano, Italy) and mounted using a fluorescence mounting medium (DAKO, Milan, Italy).
For each slice culture, the number of NeuN-positive cells was obtained by counting stacks of 25-30 images with a confocal microscope as previously described, ${ }^{17}$ and also by analyzing the cryostat tissue sections using a Zeiss Axioskop2 microscope. In both cases, the total number of NeuN-positive cells was quantified with 'eCELLence' software (Glance Vision Tech, Trieste, Italy) giving similar results as previously described. ${ }^{22}$ The number of Iba1-positive cells was analyzed using confocal microscopy, whereby a stack of five images ( $\times 40$ magnification) were counted with 'eCELLence' as previously described. ${ }^{22}$ The morphology of Iba1-positive cells was analyzed by the 'skeleton' method. ${ }^{27}$ Thus, the signal from Iba1-positive processes was enhanced to optimize their detection followed by noise de-speckling to eliminate background fluorescence. The resulting images were converted to binary data and then 'skeletonized' by using Image J software (version 1.44p c; Wayne Rasband, National Institutes of Health, Bethesda, MD, USA) as exemplified in Figure $5 c$. The AnalyzeSkeleton plugin (http://imagejdocu.tudor.lu/doku.php?id=plugin:analysis:analyzeskeleton:start) was then applied to such images to collect data on the number of branches, end points and process lengths.

The vimentin and S100 biomarker signals were collected as mean fluorescence intensity with densitometry analysis using a Zeiss Axioskop2 microscope and MetaVue software (Molecular Devices, Sunnyvale, CA, USA).

DAPI nuclear staining was used to identify the dead/dying cells quantified with 'eCELLence' software in three different regions of interest (r.o.i.), namely dorsal, central and ventral, as previously reported. ${ }^{17}$ The average percent values of nuclei with condensed chromatin were compared between different r.o.i. for control- or kainate-treated slices and normalized to the total number of nuclei.

Proliferation assay-BrdU, EdU and Ki67 staining. Various methods ${ }^{36}$ were used for assaying cell proliferation. In particular, the recently reported Click ${ }^{-}$iT EdU technique, especially advantageous because it does not require denaturing DNA or the use of antibodies, was used in accordance with the manufacturers' instructions (Invitrogen, http://products.invitrogen.com/ivgn/product/ E10187). Furthermore, we used an antibody against BrdU that binds to DNA or against the cell cycle antigen Ki67, a nuclear protein expressed by proliferating cells in G1, S, G2 and M (but not in G0) phases. ${ }^{21}$ Supplementary Figure S2a summarizes the experimental protocol. Slices were treated with a solution containing kainate $(100 \mu \mathrm{M})$ and $\mathrm{EdU}(10 \mu \mathrm{M})$ or $\operatorname{BrdU}(50 \mu \mathrm{M})$ for $1 \mathrm{~h}$; after this incubation time, slices were maintained in complete medium containing only EdU or BrdU for the following $24 \mathrm{~h}$, and then washed. Sham slices were processed in the same way except that kainate application was omitted. After fixation, cryopreservation and cryostat sectioning, incorporated EdU was detected with the fluorescentazide coupling reaction, whereby cells were incubated for $30 \mathrm{~min}$ with azide-conjugated Alexa Fluorophor in a reaction cocktail supplemented with $\mathrm{CuSO}_{4}(100 \mathrm{mM})$. Cells were then washed two times with $3 \% \mathrm{BSA}$ in PBS and nuclear-stained with Hoechst $33342(5 \mu \mathrm{g} / \mathrm{ml})$ for $30 \mathrm{~min}$ at room temperature, and finally slide-mounted using a fluorescence medium (DAKO). The counting of EdUpositive cells was done using a Zeiss Axioskop2 microscope and MetaVue software and was quantified using 'eCELLence' software. The estimation of EdUpositive cells, and the percentage of cells that were positive also for S100, DCX and NeuN markers, was done by counting manually with Image $\mathrm{J}$ software.

For BrdU quantification, ${ }^{56}$ cryostat-sectioned slices were sequentially incubated with $0.01 \mathrm{M}$ citrate buffer $\left(15 \mathrm{~min}\right.$ at $\left.90^{\circ} \mathrm{C}\right), 2 \mathrm{~N} \mathrm{HCl}\left(10 \mathrm{~min}\right.$ at $\left.37^{\circ} \mathrm{C}\right)$, neutralized by immersing them in $0.1 \mathrm{M}$ borate buffer (twice for $5 \mathrm{~min}$ at room temperature) and washed twice in $0.1 \%$ PBS-Tween-20. After this procedure, slices were processed for immunostaining with the BrdU antibody. To verify the optimal concentration and the staining procedure, we used a neuroblastoma-spinal cord subclone 34 (NSC-34) cell line, which is a hybrid cell line produced by the fusion of motor neuronenriched embryonic mouse spinal cord cells with mouse neuroblastoma cells, ${ }^{57}$ kindly donated by Dr. Silvia Di Angelantonio, University of Rome. A linear relation between the number of plated cells (counted with Counting Chamber Thoma, Vetrotecnica, Padova, Italy) and the $\mathrm{BrdU}(50 \mu \mathrm{M})$ labeled cells after $72 \mathrm{~h}$ was observed (Supplementary Figure S2b). Counting of BrdU-positive cells was performed automatically, using Volocity software (PerkinEImer Inc., Waltham, MA, USA), and manually counted using Image $\mathrm{J}$ software.

Statistics. Data were expressed as means \pm S.E.M; $n$ refers to the number of organotypic cultures slices. Statistical calculations were done using SigmaStat 3.11 (Systat Software, Chicago, IL, USA). For multiple comparisons the analysis of variance (ANOVA) test for parametric data followed by the Tukey-Kramer post hoc test was used. Non-parametric values were analyzed with the Kruskal-Wallis test. 
When two groups were compared, the Student's t-test for parametric data or the Mann-Whitney Rank Sum test for non-parametric data was applied. The accepted level of significance was always $P \leq 0.05$.

\section{Conflict of Interest}

The authors declare no conflict of interest.

Acknowledgements. We thank Dr. Beatrice Pastore for her assistance with organotypic cultures. This study was supported by grants from the government of the Friuli Venezia Giulia Region (SPINAL project).

1. Dobkin BH. Curiosity and cure: Translational research strategies for neural repair-mediated rehabilitation. Dev Neurobiol 2007; 67: 1133-1147.

2. Mehrholz J, Kugler J, Pohl M. Locomotor training for walking after spinal cord injury Cochrane Database Syst Rev 2012; 11: CD006676s.

3. Barnabé-Heider F, Frisén J. Stem cells for spinal cord repair. Cell Stem Cell 2008; 3 $16-24$

4. Ruff CA, Wilcox JT, Fehlings MG. Cell-based transplantation strategies to promote plasticity following spinal cord injury. Exp Neurol 2012; 235: 78-90.

5. Sahni V, Kessler JA. Stem cell therapies for spinal cord injury. Nat Rev Neurol 2010; 6 : 363-372.

6. Doble A. The role of excitotoxicity in neurodegenerative disease: implications for therapy. Pharmacol Ther 1999; 81: 163-221.

7. Schwartz G, Fehlings MG. Secondary injury mechanisms of spinal cord trauma: a novel therapeutic approach for the management of secondary pathophysiology with the sodium channel blocker riluzole. Prog Brain Res 2002; 137: 177-190.

8. Borgens RB, Liu-Snyder P. Understanding secondary injury. Q Rev Biol 2012; 87: 89-127.

9. Tator $\mathrm{CH}$. Update on the pathophysiology and pathology of acute spinal cord injury. Brain Pathol 1995; 5: 407-413.

10. Hugnot JP, Franzen R. The spinal cord ependymal region: a stem cell niche in the caudal central nervous system. Front Biosci 2011; 16: 1044-1059.

11. Zhao C, Deng W, Gage FH. Mechanisms and functional implications of adult neurogenesis. Cell 2008; 132: 645-660.

12. Yamamoto $\mathrm{S}$, Nagao M, Sugimori M, Kosako $\mathrm{H}$, Nakatomi $\mathrm{H}$, Yamamoto $\mathrm{N}$ et al. Transcription factor Expression and Notch-dependent regulation of neural progenitors in the adult rat spinal cord. J Neurosci 2001; 21: 9814-9823.

13. Barnabé-Heider F, Göritz C, Sabelström H, Takebayashi H, Pfrieger FW, Meletis K et al. Origin of new glial cells in intact and injured adult spinal cord. Cell Stem Cell 2010; 7 470-482.

14. Yamamoto S, Yamamoto N, Kitamura T, Nakamura K, Nakafuku M. Proliferation of parenchymal neural progenitors in response to injury in the adult rat spinal cord. Exp Neurol 2001; 172: 115-127.

15. Johe KK, Hazel TG, Muller T, Dugich-Djordjevic MM, McKay RD. Single factors direct the differentiation of stem cells from the fetal and adult central nervous system. Genes Dev 1996: 10: $3129-3140$.

16. Mazzone GL, Nistri A. Delayed neuroprotection by riluzole against excitotoxic damage evoked by kainate on rat organotypic spinal cord cultures. Neuroscience 2011; 190 318-327.

17. Mazzone GL, Nistri A. Effect of the PARP-1 Inhibitor PJ 34 on excitotoxic damage evoked by kainate on rat spinal cord organotypic slices. Cell Mol Neurobiol 2011; 31: 469-478.

18. Kiehn O. Locomotor circuits in the mammalian spinal cord. Annu Rev Neurosci 2006; 29 279-306.

19. Mazzone GL, Nistri A. Electrochemical detection of endogenous glutamate release from rat spinal cord organotypic slices as a real-time method to monitor excitotoxicity. J Neurosci Methods 2011; 197: 128-132.

20. Leukel C, Taube W, Beck S, Schubert M. Pathway-specific plasticity in the human spinal cord. Eur J Neurosci 2012; 35: 1622-1629.

21. Christie BR, Cameron HA. Neurogenesis in the adult hippocampus. Hippocampus 2006; 16: 199-207.

22. Cifra A, Mazzone GL, Nani F, Nistri A, Mladinic M. Postnatal developmental profile of neurons and glia in motor nuclei of the brainstem and spinal cord, and its comparison with organotypic slice cultures. Dev Neurobiol 2012; 72: 1140-1160.

23. Voigt $T$. Development of glial cells in the cerebral wall of ferrets: direct tracing of their transformation from radial glia into astrocytes. J Comp Neurol 1989; 289: 74-88.

24. Liu C, Wu W, Zhang B, Xiang J, Zou J. Temporospatial expression and cellular localization of glutamine synthetase following traumatic spinal cord injury in adult rats. Mol Med Rep 2013; 7: 1431-1436.

25. Yeh C-Y, Verkhratsky A, Terzieva S, Rodríguez JJ. Glutamine synthetase in astrocytes from entorhinal cortex of the triple transgenic animal model of Alzheimer's disease is not affected by pathological progression. Biogerontology 2013; e-pub ahead of print 30 August 2013.

26. Szabo M, Gulya K. Development of the microglial phenotype in culture. Neuroscience 2013: 241: 280-295.
27. Morrison HW, Filosa JA. A quantitative spatiotemporal analysis of microglia morphology during ischemic stroke and reperfusion. J Neuroinflammation 2013; 10: 4.

28. Vreugdenhil E, Kolk SM, Boekhoorn K, Fitzsimons CP, Schaaf M, Schouten T et al. Doublecortin-like, a microtubule-associated protein expressed in radial glia, is crucial for neuronal precursor division and radial process stability. Eur J Neurosci 2007; 25: 635-648.

29. Brown JP, Couillard-Després S, Cooper-Kuhn CM, Winkler J, Aigner L, Kuhn HG. Transient expression of doublecortin during adult neurogenesis. J Comp Neurol 2003; 467: $1-10$.

30. Taccola G, Margaryan G. Mladinic M, Nistri A. Kainate and metabolic perturbation mimicking spinal injury differentially contribute to early damage of locomotor networks in the in vitro neonatal rat spinal cord. Neuroscience 2008; 155: 538-555.

31. Grossman SD, Rosenberg LJ, Wrathall JR. Temporal-spatial pattern of acute neuronal and glial loss after spinal cord contusion. Exp Neurol 2001; 168: 273-282.

32. Kuzhandaivel A, Nistri A, Mazzone GL, Mladinic M. Molecular mechanisms underlying cell death in spinal networks in relation to locomotor activity after acute injury in vitro. Front Cell Neurosci 2011; 5: 9 .

33. Beck KD, Nguyen HX, Galvan MD, Salazar DL, Woodruff TM, Anderson AJ. Quantitative analysis of cellular inflammation after traumatic spinal cord injury: evidence for a multiphasic inflammatory response in the acute to chronic environment. Brain 2010; 133: 433-447.

34. Kettenmann H, Hanisch UK, Noda M, Verkhratsky A. Physiology of microglia. Physiol Rev 2011; 91: 461-553.

35. Nimmerjahn A, Kirchhoff F, Helmchen F. Resting microglial cells are highly dynamic surveillants of brain parenchyma in vivo. Science 2005; 308: 1314-1348.

36. Rose DS, Maddox PH, Brown DC. Which proliferation markers for routine immunohistology? A comparison of five antibodies. J Clin Pathol 1994; 47: 1010-1014.

37. Schwab ME. Repairing the injured spinal cord. Science 2002; 295: 1029-1031.

38. Michetti F, Corvino V, Geloso MC, Lattanzi W, Bernardini C, Serpero L et al. The S100B protein in biological fluids: more than a lifelong biomarker of brain distress. J Neurochem 2012; 120: 644-659.

39. Pérez-Gómez A, Tasker RA. Enhanced neurogenesis in organotypic cultures of rat hippocampus after transient subfield-selective excitotoxic insult induced by domoic acid. Neuroscience 2012; 208: 97-108.

40. Arvidsson A, Collin T, Kirik D, Kokaia Z, Lindvall O. Neuronal replacement from endogenous precursors in the adult brain after stroke. Nat Med 2002; 8: 963-970.

41. Bonde S, Ekdahl CT, Lindvall O. Long-term neuronal replacement in adult rat hippocampus after status epilepticus despite chronic inflammation. Eur J Neurosci 2006; 23: 965-974.

42. Vincent P, Mulle C. Kainate receptors in epilepsy and excitotoxicity. Neuroscience 2009; 158: 309-323

43. Gwak YS, Unabia GC, Hulsebosch CE. Activation of p-38alpha MAPK contributes to neuronal hyperexcitability in caudal regions remote from spinal cord injury. Exp Neurol 2009; 220: 154-161.

44. Li S, Mealing GA, Morley P, Stys PK. Novel injury mechanism in anoxia and trauma of spinal cord white matter: glutamate release via reverse $\mathrm{Na}^{+}$-dependent glutamate transport. J Neurosci 1999; 19: RC16.

45. McAdoo DJ, Xu G, Robak G, Hughes MG, Price EM. Evidence that reversed glutamate uptake contributes significantly to glutamate release following experimental injury to the rat spinal cord. Brain Res 2000; 865: 283-285

46. EIBasiouny SM, Schuster JE, Heckman CJ. Persistent inward currents in spinal motoneurons: important for normal function but potentially harmful after spinal cord injury and in amyotrophic lateral sclerosis. Clin Neurophysiol 2010; 121: 1669-1679.

47. McAdoo DJ, Hughes MG, Nie L, Shah B, Clifton C, Fullwood S et al. The effect of glutamate receptor blockers on glutamate release following spinal cord injury. Lack of evidence for an ongoing feedback cascade of damage $->$ glutamate release $->$ damage $->$ glutamate release -> etc. Brain Res 2005; 1038: 92-99.

48. Dumont RJ, Okonkwo DO, Verma S, Hurlbert RJ, Boulos PT, Ellegala DB et al. Acute spinal cord injury, part I: pathophysiologic mechanisms. Clin Neuropharmacol 2001; 24: 254-264.

49. Noble M, Mayer-Pröschel M, Davies JE, Davies SJA, Pröschel C. Cell therapies for the central nervous system: how do we identify the best candidates? Curr Opin Neurol 2011; 24: $570-576$.

50. Reeves A, Keirstead HS. Stem cell based strategies for spinal cord injury repair. Adv Exp Med Biol 2012; 760: 16-24.

51. Lukovic D, Moreno Manzano V, Stojkovic M, Bhattacharya SS, Erceg S. Concise review: human pluripotent stem cells in the treatment of spinal cord injury. Stem Cells 2012; 30: 1787-1792.

52. Stahel PF, VanderHeiden T, Finn MA. Management strategies for acute spinal cord injury: current options and future perspectives. Curr Opin Crit Care 2012; 18: 651-660.

53. Mazzone GL, Margaryan G, Kuzhandaivel A, Nasrabady SE, Mladinic M, Nistri A. Kainate-induced delayed onset of excitotoxicity with functional loss unrelated to the extent of neuronal damage in the in vitro spinal cord. Neuroscience 2010; 168: 451-462.

54. Spenger C, Braschler UF, Streit J, Luscher HR. An organotypic spinal cord - dorsal root ganglion - skeletal muscle coculture of embryonic rat. I. The morphological correlates of the spinal reflex Arc. Eur J Neurosci 1991; 3: 1037-1053.

55. Streit J, Spenger C, Luscher HR. An organotypic spinal cord - dorsal root ganglion - skeletal muscle coculture of embryonic rat. II. functional evidence for the formation of spinal reflex arcs in vitro. Eur J Neurosci 1991; 3: 1054-1068. 
56. Sadgrove MP, Laskowski A, Gray WP. Examination of granule layer cell count, cell density, and single-pulse BrdU incorporation in rat organotypic hippocampal slice cultures with respect to culture medium, septotemporal position, and time in vitro. J Comp Neurol 2006; 497: 397-415.

57. Cashman NR, Durham HD, Blusztajn JK, Oda K, Tabira T, Shaw IT et al. Neuroblastoma x spinal cord (NSC) hybrid cell lines resemble developing motor neurons. Dev Dyn 1992 194: 209-221.
Cell Death and Disease is an open-access journal published by Nature Publishing Group. This work is licensed under a Creative Commons Attribution-NonCommercialNoDerivs 3.0 Unported License. To view a copy of this license, visit http://creativecommons.org/licenses/by-nc-nd/3.0/

Supplementary Information accompanies this paper on Cell Death and Disease website (http://www.nature.com/cddis) 